\title{
Maternal nutritional risk factors for small for gestational age babies in a developed country: a case-control study
}

\author{
E A Mitchell, E Robinson, P M Clark, D M O Becroft, N Glavish, N S Pattison, J E Pryor, \\ J M D Thompson, C J Wild
}

Arch Dis Child Fetal Neonatal Ed 2004;89:F431-F435. doi: 10.1136/adc.2003.036970

See end of article for authors' affiliations ....................

Correspondence to: Professor Mitchell, Department of Paediatrics, University of Auckland,

Private Bag 92019 , Auckland, New Zealand; e.mitchell@auckland.ac.nz

Accepted

24 November 2003
Aims: To assess the effect of maternal diet during pregnancy on the risk of delivering a baby who is small for gestational age (SGA).

Methods: Case-control study of 844 cases (SGA) and 870 controls (appropriate size for gestational age (AGA)). Only term (37+ completed weeks of gestation) infants were included. Retrospective food frequency questionnaires were completed at birth on the diet at the time of conception and in the last month of pregnancy.

Results: At the time of conception, mothers of AGA infants ate significantly more servings of carbohydrate rich food and fruit, and were more likely to have taken folate and vitamin supplements than mothers of SGA infants. There was some evidence that mothers of AGA infants also ate more servings of dairy products, meat, and fish $(0.05<\mathrm{p}<0.1)$. However, after adjustment for maternal ethnicity, smoking, height, weight, hypertension, and occupation, fish intake $(p=0.04)$, carbohydrate-rich foods $(p=0.04)$, and folate supplementation ( $p=0.02$ ) were associated with a reduced risk of SGA. In the last month of pregnancy, only iron supplementation was associated with a reduced risk of SGA $(p=0.05)$ after adjustment for potential confounders.

Conclusions: This study suggests that small variations in maternal diets within the normal range during pregnancy in developed countries are associated with differences in birth weight. ow birth weight is a consequence of being born too small or too early. Babies born small for gestational age (SGA) - are at increased risk of death and developmental and behavioural problems in childhood. ${ }^{1}$ Furthermore, these infants are at increased risk of non-insulin dependent diabetes mellitus and cardiovascular disease in adult life. ${ }^{2}$ The causes of SGA are not well established. ${ }^{3}$ Clearly genetic abnormalities and intrauterine infections or toxicity are factors in some cases. However, for most SGA infants the cause is thought to be reduced substrate delivery to the fetus, because of either abnormalities of the fetus or placenta or poor nutrition of the mother.

The effect of severe malnutrition on birth weight depends on the stage of gestation. In the Netherlands in 1944-1945, famine during the first trimester was associated with increased placental weight but no change in birth weight, whereas famine later in pregnancy was associated with a reduction in both placental and birth weight. ${ }^{4}$ However, even in developed countries, a small increase in birth weight has been seen with balanced protein energy supplementation in pregnancy. ${ }^{5}$

Lower birth weight is associated with lower socioeconomic status. ${ }^{6}$ How much of this is explained by maternal nutrition is unknown, as maternal nutrition and socioeconomic status are associated with many other factors, such as maternal smoking.

The aim of this study was to assess the effect of maternal diet and supplements of vitamins, folate, and iron in early and late pregnancy on the risk of delivering SGA babies.

\section{METHODS}

This case-control study has been described in detail previously. ${ }^{7}$ In brief, between 16 October 1995 and 12 August 1996 babies born and resident in the Waitemata Health or Auckland Healthcare regions were eligible for inclusion, and from 12 August 1996 to 30 November 1997 babies born in the Auckland Healthcare region were eligible to participate. Preterm infants ( $<37$ completed weeks of gestation), multiple births, and those with congenital abnormalities were excluded. All SGA infants and a random sample of infants of appropriate size for gestational age (AGA) were selected. SGA was defined as equal to or below the sex specific 10th centile for gestational age in the New Zealand population. ${ }^{8}$ AGA babies weighed more than the 10th centile. Gestation was estimated using the date of the last menstrual period if it was available and was within two weeks of the best clinical estimate of gestational age at birth; otherwise the best clinical estimate was used.

Data were collected by (a) interviewer administered questionnaire shortly after delivery, $(b)$ self administered food frequency questionnaire (FFQ), and (c) obstetric databases.

A FFQ was used to assess diet. This was based on the Life in New Zealand survey. ${ }^{9}$ The mothers were asked to recall their diet at the time of conception ("about the time you became pregnant") and in the last month of pregnancy. Food frequencies for individual questions were converted into servings a day or week and then summed to give a total daily (or weekly) intake for seven food groups. These food groups were fresh fruit (including bananas, apples, pears, citrus fruits, stone fruits, berries, melon, and avocados), vegetables (green and root vegetables, peas, corn, lentils), carbohydrate rich food (potatoes, rice, noodles, pasta, bread, breakfast cereals), high carbohydrate snacks and soft drinks (including biscuits, potato crisps, cakes, soft drinks), meat (including meat products), fish (including shellfish), and dairy products (milk, cheese, and yoghurt). If all the answers to the questions making up a food group were missing, the intake

Abbreviations: AGA, appropriate size for gestational age; $F F Q$, food frequency questionnaire; SGA, small for gestational age 
was specified as missing. If only some of the answers were missing, they were designated as "not at all" — that is, given a zero intake score-and the total intake calculated. Vitamin, folate, and iron supplements were recorded as taken at least once a week.

Mann-Witney U tests were used to investigate differences in daily intake of the food groups between mothers of SGA and AGA infants. $\chi^{2}$ tests were used to investigate the association between having an SGA infant and the use of supplements. Logistic regression models were used to investigate whether maternal food intake had an effect on whether or not the infant was SGA after controlling for socioeconomic status, ethnicity, maternal height, maternal weight before pregnancy, maternal hypertension, and maternal smoking. In the logistic regressions, the daily intake was categorised.

The occupation of the mother and her partner was self reported. Socioeconomic status was defined using the subject's occupation, or that of her partner if higher using the Elly Irving classification of occupation. ${ }^{10}$ Social classes I and II were categorised as high, III and IV as middle, and V, VI, and others as low. Ethnic group was the self reported ethnicity collected by the obstetric hospitals from the mothers during their pregnancy. The options available were Maori, European, Pacific Islanders, Indian, Chinese, other.

The study was approved by the North Health research ethics committee.

\section{Diet recall study}

Ninety one women were recruited early in pregnancy and completed a FFQ about their dietary intake around the time of conception. At the time of the birth of the child, they were asked to complete the same questionnaire recalling the same time period. For each food group, the median number of servings was compared, as was the distribution of the responses.

\section{RESULTS}

A total of 2182 infants were eligible for this study, and the parents of $1714(78.6 \%)$ completed the interviewer administered questionnaire (844 SGA and 870 AGA). Of these 1714, $1691(98.7 \%)$ allowed access to their obstetric records and the records were found. Table 1 shows the characteristics of the mothers in the study population. Overall, $67 \%$ and $66 \%$ of
Table 2 Median number of servings for mothers of small for gestational age (SGA) and appropriate size for gestational age (AGA) infants at the time of conception and last month of pregnancy

\begin{tabular}{llll} 
& SGA & AGA & p Value* \\
\hline At the time of conception & & & \\
$\quad$ Fruit per day & 1.4 & 1.5 & 0.03 \\
$\quad$ Vegetables per day & 1.4 & 1.6 & 0.11 \\
Meat per week & 4.0 & 4.5 & 0.09 \\
Fish per week & 0.5 & 1.0 & 0.08 \\
Dairy products per day & 2.2 & 2.5 & 0.056 \\
Carbohydrate rich foods per day & 2.8 & 3.1 & 0.004 \\
High carbohydrate snacks and soft & 1.4 & 1.4 & 0.10 \\
drinks per day & & & \\
Last month of pregnancy & & & \\
$\quad$ Fruit per day & 1.9 & 2.1 & 0.007 \\
Vegetables per day & 1.6 & 1.6 & 0.30 \\
$\quad$ Meat per week & 4.2 & 4.2 & 0.64 \\
Fish per week & 0.5 & 0.5 & 0.48 \\
$\quad$ Dairy products per day & 2.8 & 3.0 & 0.05 \\
Carbohydrate rich foods per day & 3.0 & 3.3 & 0.002 \\
$\quad$ High carbohydrate snacks and soft & 1.5 & 1.8 & 0.046 \\
drinks per day & & & \\
\hline * Mann-Whitney U test. & & & \\
\hline
\end{tabular}

subjects completed the FFQ for the time relating to the time of conception and for the last month of pregnancy respectively.

Around the time of conception, mothers of AGA infants ate significantly more servings of carbohydrate rich foods, fruit, and dairy products (univariate analyses, table 2), and were more likely to take folate (odds ratio (OR) 1.61; 95\% confidence interval (CI) 1.22 to 2.08) and vitamin (OR $1.35 ; 95 \%$ CI 1.02 to 1.78 ) supplements than mothers of SGA infants. There was some evidence that mothers of AGA infants also ate more servings of meat and fish $(0.05<\mathrm{p}<0.1)$ (table 2). However, after adjustment for ethnicity, smoking, height, weight, hypertension, and socioeconomic status, fish intake $(p=0.04)$, carbohydrate rich foods $(p=0.04)$, and folate supplementation (table $3, p=0.02$ ) were associated with a reduced risk of SGA.

In the last month of pregnancy at the univariate level mothers of AGA infants consumed significantly more servings of carbohydrate rich foods, high carbohydrate snacks and soft drinks, fruit, dairy products, and vitamin

\begin{tabular}{|c|c|c|c|c|c|}
\hline & \multicolumn{2}{|l|}{ SGA } & \multicolumn{2}{|l|}{ AGA } & \multirow[b]{2}{*}{ OR $(95 \% \mathrm{Cl})$} \\
\hline & $n$ & $(\%)$ & $\bar{n}$ & (\%) & \\
\hline \multicolumn{5}{|l|}{ Socioeconomic group } & \multirow{13}{*}{$\begin{array}{l}\chi^{2}=25.2, p<0.001 \\
1.00 \\
1.60(1.29 \text { to } 1.98) \\
1.69(1.30 \text { to } 2.19) \\
\chi^{2}=89.9, p<0.001 \\
1.00 \\
1.86(1.34 \text { to } 2.58) \\
0.72(0.55 \text { to } 0.95) \\
4.36(2.86 \text { to } 6.64) \\
1.87(1.38 \text { to } 2.53) \\
\chi^{2}=43.3, p<0.001 \\
1.00 \\
2.11 \text { (1.69 to } 2.64)\end{array}$} \\
\hline High & 348 & $(41.2)$ & 464 & (53.4) & \\
\hline Middle & 319 & (37.8) & 266 & (30.5) & \\
\hline Low & 177 & (19.0) & 140 & (15.1) & \\
\hline Ethnicity & & & & & \\
\hline European & 385 & $(45.7)$ & 486 & $(56.0)$ & \\
\hline Maori & 106 & (12.6) & 72 & (8.3) & \\
\hline Pacific & 106 & (12.6) & 185 & (21.3) & \\
\hline Indian & 107 & (12.7) & 31 & (3.6) & \\
\hline Chinese, other Asian, others & 139 & (16.5) & 94 & (10.8) & \\
\hline Smoking & & & & & \\
\hline No & 547 & (66.4) & 683 & (80.5) & \\
\hline \multirow[t]{2}{*}{ Yes } & 277 & (33.6) & 165 & (19.5) & \\
\hline & Mean & (SD) & Mean & (SD) & t Value, $p$ value \\
\hline Age (years) & 29.1 & (5.7) & 30.3 & (5.5) & $4.75,<0.001$ \\
\hline Height $(\mathrm{m})$ & 1.62 & $(0.07)$ & 1.65 & (0.07) & $10.08,<0.001$ \\
\hline Weight (kg) & 59.8 & (13.7) & 66.5 & (14.5) & $9.85,<0.001$ \\
\hline
\end{tabular}


Table 3 Number and multivariate odds ratios for small for gestational age (SGA) for servings for each food group at the time of conception

\begin{tabular}{|c|c|c|c|c|}
\hline Food group & SGA & AGA & Multivariate OR $(95 \% \mathrm{Cl})$ & \\
\hline Fruit & $\mathrm{n}=542$ & $\mathrm{n}=600$ & & $p=0.12, d f=4, \chi^{2}=7.27$ \\
\hline $0-0.75$ & 132 & 104 & 1.49 (1.00 to 2.24$)$ & \\
\hline$>0.75-1.25$ & 107 & 144 & $0.99(0.67$ to 1.47$)$ & \\
\hline$>1.25-2.0$ & 115 & 117 & $1.44(0.96$ to 2.17$)$ & \\
\hline$>2.0-3.0$ & 84 & 96 & $1.23(0.80$ to 1.90$)$ & \\
\hline$>3$ & 104 & 139 & 1 & \\
\hline Vegetables & $\mathrm{n}=539$ & $\mathrm{n}=598$ & & $p=0.32, d f=4, \chi^{2}=4.71$ \\
\hline $0-0.75$ & 138 & 137 & 1.25 (0.79 to 1.97$)$ & \\
\hline$>0.75-1.25$ & 93 & 81 & $1.58(0.97$ to 2.58$)$ & \\
\hline$>1.25-2.0$ & 87 & 104 & $1.12(0.70$ to 1.80$)$ & \\
\hline$>2.0-3.0$ & 126 & 190 & $1.40(0.91$ to 2.14$)$ & \\
\hline$>3$ & 99 & 86 & 1 & \\
\hline Meat & $n=533$ & $n=598$ & & $p=0.79, d f=4, \chi^{2}=1.71$ \\
\hline $0-2$ & 60 & 42 & $1.36(0.80$ to 2.29$)$ & \\
\hline$>2-4$ & 180 & 193 & $1.07(0.76$ to 1.51$)$ & \\
\hline$>4-5$ & 85 & 114 & 0.97 (0.64 to 1.45$)$ & \\
\hline$>5-6$ & 71 & 81 & 1.01 (0.65 to 1.56$)$ & \\
\hline$>6$ & 137 & 168 & 1 & \\
\hline Fish & $\mathrm{n}=529$ & $\mathrm{n}=592$ & & $p=0.04, d f=2, \chi^{2}=6.68$ \\
\hline None & 110 & 84 & 1.69 (1.07-2.69) & \\
\hline Up to one & 312 & 382 & 1.09 (0.75 to 1.58$)$ & \\
\hline More than one & 107 & 126 & 1 & \\
\hline Dairy products & $\mathrm{n}=533$ & $n=597$ & & $p=0.21, d f=4, \chi^{2}=5.83$ \\
\hline $0-1.25$ & 108 & 92 & 1.13 (0.75 to 1.72$)$ & \\
\hline$>1.25-2.0$ & 115 & 121 & 1.09 (0.73 to 1.62$)$ & \\
\hline$>2.0-3.0$ & 114 & 152 & $0.81(0.55$ to 1.19$)$ & \\
\hline$>3.0-4.0$ & 70 & 103 & $0.74(0.48$ to 1.14$)$ & \\
\hline$>4.0$ & 117 & 125 & 1 & \\
\hline $\begin{array}{l}\text { Carbohydrate rich } \\
\text { foods }\end{array}$ & $\mathrm{n}=538$ & $\mathrm{n}=598$ & & $p=0.04, d f=4, \chi^{2}=10.37$ \\
\hline $0-1.5$ & 154 & 127 & $1.31(0.88$ to 1.97$)$ & \\
\hline$>1.5-2.25$ & 114 & 109 & $1.22(0.80$ to 1.86$)$ & \\
\hline$>2.25-2.75$ & 105 & 147 & $0.81(0.54$ to 1.23$)$ & \\
\hline$>2.75-3.5$ & 70 & 108 & $0.77(0.49$ to 1.21$)$ & \\
\hline$>3.5$ & 96 & 107 & 1 & \\
\hline $\begin{array}{l}\text { High carbohydrate } \\
\text { snacks and soft drinks }\end{array}$ & $n=538$ & $n=597$ & & $p=0.35, d f=3, \chi^{2}=3.31$ \\
\hline $0-<1$ & 189 & 197 & $1.27(0.85$ to 1.91$)$ & \\
\hline $1-<2$ & 172 & 171 & $1.37(0.91$ to 2.06$)$ & \\
\hline $2-<3$ & 101 & 132 & $1.06(0.68$ to 1.65$)$ & \\
\hline$\geqslant 3$ & 72 & 97 & 1 & \\
\hline Vitamins & $\mathrm{n}=529$ & $\mathrm{n}=593$ & & $p=0.09, d f=1, \chi^{2}=2.81$ \\
\hline Yes & 124 & 173 & 0.78 (0.58 to 1.04$)$ & \\
\hline No & 405 & 420 & 1 & \\
\hline Folate supplement & $n=503$ & $n=573$ & & $p=0.02, d f=1, \chi^{2}=5.58$ \\
\hline Yes & 139 & 220 & $0.70(0.52$ to 0.94$)$ & \\
\hline No & 349 & 345 & 1 & \\
\hline Iron supplement & $n=497$ & $n=562$ & & $p=0.81, d f=1, \chi^{2}=0.06$ \\
\hline Yes & 98 & 90 & $1.05(0.73$ to 1.50$)$ & \\
\hline No & 399 & 472 & 1 & \\
\hline
\end{tabular}

supplementation (OR $1.35: 95 \%$ CI 1.01 to 1.85 ) than mothers of SGA infants (table 2). However, after adjustment for potential confounders only iron supplementation was associated with a reduced risk of SGA (table $4, \mathrm{p}=0.05$ ).

\section{Diet recall study}

Eighty women completed questionnaires during early pregnancy (mean (SD) gestation 8.2 (1.9) weeks) and after the birth of the child (mean (SD) age 1.4 (1.3) weeks).

The median number of servings for each food group did not differ markedly between the two recorded times; however, there was a tendency for mothers to recall slightly lower quantities of dairy products, meat, and carbohydrate rich foods (table 5).

\section{DISCUSSION}

Limitations in this study must be recognised. We have previously shown that non-respondents were more likely to be mothers of SGA infants than mothers of AGA babies $(22.3 \% \vee 16.6 \%)$ and that non responders are more likely to be smokers. ${ }^{7}$ Furthermore, among the subjects who were interviewed, non-Europeans were less likely to complete the FFQs. Secondly, FFQs have considerable measurement error, as do most dietary assessment tools. ${ }^{11}$ Studies of nutritional effects using FFQs tend to be notoriously underpowered even when conventional methods of adjusting for measurement error are used. However, FFQ was chosen as we were particularly interested in the diet around the time of conception, and it would not have been feasible to identify sufficient women in early pregnancy to use the seven day semiquantitative food diary or weighed food records. Furthermore, diet at the time of conception was recalled about nine months later. However, we have shown that this does not introduce a systematic error, although it does increase measurement error. The strengths of this study are the large sample size and large number of SGA babies.

After adjustment for potential confounders, mothers of AGA infants ate more servings of fish $(p=0.04)$ and carbohydrate rich foods $(\mathrm{p}=0.04)$ and more used supplements of folic acid ( $\mathrm{p}=0.02)$ in early pregnancy. 
Table 4 Number and multivariate odds ratios for small for gestational age (SGA) for servings for each food group in the last month of pregnancy

\begin{tabular}{|c|c|c|c|c|}
\hline Food group & SGA & AGA & Multivariate OR $(95 \% \mathrm{Cl})$ & \\
\hline Fruit & $\mathrm{n}=540$ & $\mathrm{n}=598$ & & $p=0.19, d f=4, \chi^{2}=6.11$ \\
\hline $0-0.75$ & 95 & 62 & 1.53 (0.99 to 2.35$)$ & \\
\hline$>0.75-1.25$ & 82 & 83 & 1.08 (0.72 to 1.63$)$ & \\
\hline$>1.25-2.0$ & 111 & 136 & $0.93(0.61$ to 1.40$)$ & \\
\hline$>2.0-3.0$ & 89 & 123 & 1.04 (0.69 to 1.57$)$ & \\
\hline$>3$ & 163 & 194 & 1 & \\
\hline Vegetables & $n=539$ & $\mathrm{n}=598$ & & $p=0.12, d f=4, \chi^{2}=7.25$ \\
\hline $0-0.75$ & 146 & 126 & 1.20 (0.76 to 1.92$)$ & \\
\hline$>0.75-1.25$ & 76 & 84 & $0.94(0.57$ to 1.56$)$ & \\
\hline$>1.25-2.0$ & 91 & 132 & $0.69(0.43$ to 1.10$)$ & \\
\hline$>2.0-3.0$ & 159 & 183 & $0.98(0.64$ to 1.51$)$ & \\
\hline$>3.0$ & 67 & 73 & 1 & \\
\hline Meat & $\mathrm{n}=534$ & $n=597$ & & $p=0.66, d f=4, \chi^{2}=2.44$ \\
\hline $0-2$ & 56 & 57 & $0.70(0.43$ to 1.16$)$ & \\
\hline$>2-4$ & 177 & 202 & $0.84(0.59$ to 1.19$)$ & \\
\hline$>4-5$ & 102 & 123 & 0.85 (0.57 to 1.26$)$ & \\
\hline$>5-6$ & 66 & 72 & 0.97 (0.62 to 1.53$)$ & \\
\hline$>6$ & 133 & 143 & 1 & \\
\hline Fish & $\mathrm{n}=529$ & $\mathrm{n}=593$ & & $p=0.39, d f=2, \chi^{2}=1.90$ \\
\hline None & 138 & 137 & $1.29(0.83$ to 1.99$)$ & \\
\hline Up to one & 284 & 344 & $1.07(0.73$ to 1.57$)$ & \\
\hline More than one & 144 & 112 & 1 & \\
\hline Dairy products & $n=536$ & $n=596$ & & $p=0.38, d f=4, \chi^{2}=4.22$ \\
\hline $0-1.25$ & 77 & 64 & 1.21 (0.78 to 1.87$)$ & \\
\hline$>1.25-2.0$ & 81 & 85 & $1.08(0.72$ to 1.63$)$ & \\
\hline$>2.0-3.0$ & 130 & 144 & 0.98 (0.69 to 1.40$)$ & \\
\hline$>3.0-4.0$ & 158 & 124 & $0.76(0.52$ to 1.19$)$ & \\
\hline$>4.0$ & 102 & 175 & 1 & \\
\hline $\begin{array}{l}\text { Carbohydrate rich } \\
\text { foods }\end{array}$ & $\mathrm{n}=539$ & $\mathrm{n}=598$ & & $\mathrm{p}=0.17, \mathrm{df}=4, \chi^{2}=6.48$ \\
\hline $0-1.5$ & 123 & 101 & 1.52 (0.99 to 2.33 ) & \\
\hline$>1.5-2.25$ & 96 & 100 & $1.36(0.87$ to 2.13$)$ & \\
\hline$>2.25-2.75$ & 114 & 125 & $1.08(0.71$ to 1.65$)$ & \\
\hline$>2.75-3.5$ & 118 & 170 & $1.00(0.67$ to 1.51$)$ & \\
\hline$>3.5$ & 89 & 102 & 1 & \\
\hline $\begin{array}{l}\text { High carbohydrate } \\
\text { snacks and soft drinks }\end{array}$ & $\mathrm{n}=538$ & $n=597$ & & $p=0.22, d f=3, \chi^{2}=4.40$ \\
\hline $0-<1$ & 173 & 155 & $1.26(0.86$ to 1.85$)$ & \\
\hline $1-<2$ & 165 & 184 & $1.18(0.81$ to 1.71$)$ & \\
\hline $2-<3$ & 100 & 137 & 0.88 (0.58 to 1.32$)$ & \\
\hline$\geqslant 3$ & 100 & 121 & 1 & \\
\hline Vitamins & $n=526$ & $n=591$ & & $p=0.1, d f=1, \chi^{2}=2.78$ \\
\hline Yes & 97 & 139 & $0.76(0.55-1.05)$ & \\
\hline No & 429 & 452 & 1 & \\
\hline Folate supplement & $n=473$ & $n=546$ & & $p=0.2, d f=1, \chi^{2}=1.65$ \\
\hline Yes & 33 & 38 & $0.70(0.41$ to 1.20$)$ & \\
\hline No & 440 & 508 & 1 & \\
\hline Iron supplement & $\mathrm{n}=507$ & $\mathrm{n}=579$ & & $p=0.05, d f=1, \chi^{2}=3.71$ \\
\hline Yes & 185 & 220 & $0.76(0.57$ to 1.01$)$ & \\
\hline No & 322 & 359 & 1 & \\
\hline
\end{tabular}

The strongest association was found with folic acid supplementation. Folic acid is thought to be important for fetal growth. ${ }^{12}$ Our finding is consistent with some randomised

Table 5 Diet recall study: difference in servings at the time of conception recorded in early pregnancy compared with that recalled at the time of the birth of child

\begin{tabular}{lll}
\hline & Median & $\begin{array}{c}\text { Lower quartile, } \\
\text { upper quartile }\end{array}$ \\
\hline Fruit a day & 0.0 & $-0.57,0.57$ \\
Vegetables a day & 0.0 & $-0.82,0.25$ \\
Meat a week & 0.5 & $-1.0,1.5$ \\
Fish a week & 0.0 & $-0.5,0.0$ \\
Dairy products a day & 0.40 & $-0.09,1.04$ \\
Carbohydrate rich foods a day & 0.25 & $-0.14,0.96$ \\
High carbohydrate snacks and soft & 0.07 & $-0.28,0.78$ \\
drinks a day & & \\
\hline
\end{tabular}

controlled studies which have shown that folic acid supplementation increases birth weight, ${ }^{13}$ although a Cochrane review found a non- significant reduction in low birth weight in controlled trials of folate supplementation. ${ }^{14}$ In developed countries, there is a well established association between folate status of pregnant women and the birth weight of their infant. ${ }^{15}$ Folic acid intake from the diet is thought to be marginal in many pregnant women in developed countries. ${ }^{16}$

The finding that fish intake in early pregnancy was associated with a lower risk of SGA was in keeping with observations from Scandinavia that women who eat a lot of fish tend to have heavier babies. ${ }^{17}{ }^{18}$ It is postulated that the high intake of omega-3 oils affects prostaglandin synthesis, leading to prolonged pregnancies as well as babies that are heavier for gestational age. An interventional study found that a fish oil supplementation reduced the recurrence risk of preterm birth, but had no effect on intrauterine growth retardation. ${ }^{19}$ Fish is expensive in New Zealand, and the amount of fish eaten in our cohort was generally small. Our 
findings suggest that in New Zealand even a modest fish intake in pregnancy is associated with a reduced risk of having a growth restricted baby.

The number of servings of carbohydrate rich foods in early pregnancy was associated with a reduced risk of SGA $(p=0.04)$. The evidence linking variations in carbohydrate intake of supposedly well nourished women with size of their babies at birth is contradictory. Our results contrast with the prospective observational study of Godfrey et al. ${ }^{20}$ That study found that mothers with a high carbohydrate intake in early pregnancy had lighter babies. Matthews et al, ${ }^{21}$ in another prospective study set like that of Godfrey et al in the south of England, failed to find any relation between size at birth and the intake of any macronutrient. The authors looked at macronutrients and micronutrients derived from a semiquantitative seven day food diary and from extensive FFQs respectively. Given the retrospective nature of this part of our study, we felt it prudent to describe the foods eaten, rather than extrapolate to their constituent parts. Thus our measure of carbohydrate intake will not be directly comparable to that of Godfrey et al. In rural India where maternal undernutrition is common, no association was seen with maternal energy intake and size at birth. ${ }^{15}$

In contrast with the findings at the time of conception, there were few associations with SGA when the diet in the last month of pregnancy was considered. Only oral iron supplementation was significantly associated with a reduced risk of SGA after adjustment for potential confounders $(p=0.05)$. This finding contrasts with the conclusion of a review that iron supplementation of anaemic or non-anaemic pregnant women does not increase birth weight. ${ }^{22}$ It is also consistent with previous studies in developed countries that have assessed diet in late pregnancy, which have concluded that maternal nutrition does not have an important effect on birth weight. Godfrey et $a l^{20}$ also found that there was no univariate association between nutrient intake in late pregnancy and either birth weight or placental weight.

In summary, after allowing for factors known to be associated with SGA in this cohort, we have shown that eating more fish and carbohydrate rich foods and taking folate supplements around the time of conception is associated with a reduced risk of having an SGA baby. Iron supplements in late pregnancy are also associated with a reduced risk. This study suggests that small variations in maternal diet in early pregnancy could have important effects on birth weight and even on later health outcomes.

\section{ACKNOWLEDGEMENTS}

This study was funded by the Health Research Council of New Zealand (HRC), the Foundation for the Newborn, and the Hawkes Bay Medical Research Foundation. EAM is supported in part by the Child Health Research Foundation. The study was coordinated by Ms K Rees. We sincerely thank the mothers who took part.

\section{Authors' affiliations}

E A Mitchell, P M Clark, J M D Thompson, D M O Becroft, Department of Paediatrics, University of Auckland, Auckland, New Zealand

E Robinson, Department of Community Health, Private Bag 92019, University of Auckland

C J Wild, Department of Statistics, University of Auckland

D M O Becroft, N S Pattison, Department of Obstetrics \& Gynaecology, University of Auckland

N Glavish, He Kamaka Oranga, Maori Health Management, Green Lane Hospital, Auckland

J E Pryor, Department of Behavioural and Developmental Psychology, University of Auckland

\section{REFERENCES}

1 Allen MC. Developmental outcomes and follow-up of small-for-gestational infants. Semin Perinatol 1984;8:123-56.

2 Barker DJ, Gluckman PD, Godfrey KM, et al. Fetal nutrition and cardiovascular disease in adult life. Lancet 1993;341:938-41.

3 Kramer MS. Determinants of low birth weight: methodological assessment and meta-analysis. Bull WHO 1987;65:663-737.

4 Lumey LH. Compensatory placental growth after restricted maternal nutrition in early pregnancy. Placenta 1998;19:105-11.

5 Kramer MS. Balanced protein/energy supplementation in pregnancy (Cochrane Review). Cochrane Library. Issue 4. Oxford: Update Software, 2002.

6 Spencer N, Logan S. Social influences on birth weight. Arch Dis Child Fetal Neonatal Ed 2002;86:F6-7.

7 Thompson JMD, Clark PM, Robinson E, et al. Risk factors for small for gestational age babies: the Auckland Birth weight Collaborative (ABC) Study. J Paediatr Child Health 2001;37:369-75.

8 Thompson JMD, Mitchell EA. Sex specific birthweight percentiles by gestational age for New Zealand. N Z Med J 1994;107:1-3.

9 Life in New Zealand. Commission report prepared by University of Otago. Wellington: Hillary Commission for Recreation and Sport, 1991

10 Elley WB, Irving JC. Revised socioeconomic index for New Zealand. New Zealand Journal of Educational Studies 1976;11:25-30.

11 Kipnis V, Subar A, Midthune D, et al. Dietary measurement error and its implications: results of the OPEN biomarker study. FASEB J 2002;16:A27.

12 Tamura T. Nutrient interactions between folate and zinc or copper: their possible implications to pregnancy outcome. In: Massaro EJ, Rogers JM, eds. Folate and human development. Clifton, NJ: Humana Press, 2002:219-40.

13 Rolschau J, Kristoffersen K, Ulrich M, et al. The influence of folic acid supplement on the outcome of pregnancies in the county of Funen in Denmark. Part I. Eur J Obstet Gynecol Reprod Biol 1999;87:105-10.

14 Mahomed K. Folate supplementation in pregnancy (Cochrane Review). Cochrane Library. Issue 4. Oxford: Update Software, 2002.

15 Ek J. Plasma and red cell folate in mothers and infants in normal pregnancies. Relation to birth weight. Acta Obstet Gynecol Scand 1982;61:17-20.

16 Gonzalez-Gross M, Prinz-Langenohl R, Pietrzik K. Folate status in Germany 1997-2000. Int J Vitam Nutr Res 2002;72:351-9.

17 Olsen SF, Olsen J, Frische G. Does fish consumption during pregnancy increase fetal growth? A study of the size of the newborn, placental weight and gestational age in relation to fish consumption during pregnancy. Int J Epidemiol 1990;19:971-7.

18 Olsen SF, Secher NJ. Low consumption of seafood in early pregnancy as a risk factor for preterm delivery: prospective cohort study. BMJ 2002;324:447

19 Olsen SF, Secher NJ, Tabor A, et al. Randomised clinical trials of fish oil supplementation in high risk pregnancies. Fish Oil Trials In Pregnancy (FOTIP) Team. BJOG 2000;107:382-95.

20 Godfrey K, Robinson S, Barker DJP, et al. Maternal nutrition in early and late pregnancy in relation to placental and fetal growth. BMJ 1996;312:410-14.

21 Mathews F, Yudkin P, Neil A. Influence of maternal nutrition on outcome of pregnancy: prospective cohort study. BMJ 1999;319:339-43.

22 Rasmussen KM. Is there a causal relationship between iron deficieny or irondeficiency anaemia and weight at birth, length of gestation and perinatal mortality? J Nutr 2001;131:590S-603S. 